\title{
Pengaruh Teknik Skarifikasi Fisik dan Media Perkecambahan terhadap Daya Berkecambah Benih Pala (Myristica fragrans)
}

\author{
The Effects of Physical Scarification Technique and Germinating Substrate on Nutmeg \\ (Myristica fragrans) Seed Germination Potency
}

\section{Dwi Gery Febriyan, Eny Widajati*}

Departemen Agronomi dan Hortikultura, Fakultas Pertanian, Institut Pertanian Bogor (Bogor Agricultural University), Jl. Meranti, Kampus IPB Darmaga, Bogor 16680, Indonesia Telp. \& Faks.62-251-8629353 e-mail agronipb@indo.net.id *Penulis untuk korespondensi: eny_widajati@yahoo.co.id

Disetujui 7 Januari 2015/ Publish online 15 januari 2015

\begin{abstract}
The objective of this experiment is studying the effect of physical scarification of nutmeg seed coat and germination media to accelerating germination rate and enhancing nutmeg seed viability. This experiment was conducted in December 2013 until May 2014 at Leuwikopo Experimental Field's green house and Seed Laboratory of Agronomy and Horticulture Department, Faculty of Agriculture, Bogor Agricultural University. This experiment was using factorial randomize complete block design with 3 replications. The first factor was physical scarification on the seed coat with three levels: without scarification, one hole scarification on seed's base, and two holes scarifications on seed's base. The Second factor was the seed germination substrate that consist of sand, charcoal of husk rice, and mixture of sand and compost 1:1 (v/v). The results showed that two holes physical scarification could enhance germination process according to the earlier appearance of roots and shoot. Sand as the germinating substrate was observed as a better substrate according to the parameters of germinating potency and shoot height. Two holes physical scarification treatment which was sowed in sand substrate showed the increase of lateral root number into 6 lateral roots. Nutmeg seedling growth from sand substrate seedling showed a better growth than the charcoal of husk rice substrate seedling by evaluating these parameters on stem diameter, seedling's height, amount of leaves, canopy's width, and leaves colour.
\end{abstract}

Keywords: Myristicaceae, nutmeg germinated seedling, seed coat treatment

\section{ABSTRAK}

Percobaan ini bertujuan mempelajari perlakuan skarifikasi fisik kulit benih pala dan penggunaan media perkecambahan dalam upaya mempercepat perkecambahan dan meningkatkan viabilitas benih pala. Percobaan dilaksanakan bulan Desember 2013 hingga Mei 2014 di rumah kaca Kebun Percobaan Leuwikopo dan Laboratorium Benih Departemen Agronomi dan Hortikultura, Fakultas Pertanian, Institut Pertanian Bogor. Rancangan percobaan yang digunakan adalah RKLT Faktorial. Percobaan terdiri dari dua faktor dengan tiga ulangan. Faktor pertama adalah perlakuan skarifikasi fisik kulit benih dengan tiga taraf, yaitu tanpa perlakuan skarifikasi, skarifikasi satu lubang bagian pangkal benih, dan skarifikasi dua lubang bagian ujung dan pangkal benih. Faktor kedua adalah jenis media perkecambahan benih yang terdiri dari tiga taraf, yakni pasir, arang sekam, dan campuran antara pasir dengan kompos 1:1 (v/v). Hasil percobaan menunjukkan perlakuan skarifikasi fisik dua lubang dapat meningkatkan perkecambahan benih pala berdasarkan kemunculan akar dan tunas yang lebih awal. Media pasir merupakan media yang nyata lebih baik berdasarkan tolok ukur daya berkecambah dan tinggi tunas. Skarifikasi benih pala dua lubang yang ditanam di media pasir menunjukkan jumlah akar lateral nyata lebih banyak sejumlah enam buah. Pertumbuhan bibit berasal dari media pasir lebih baik dibandingkan kecambah yang berasal dari media arang sekam pada parameter diameter batang, tinggi bibit, jumlah daun, lebar tajuk, dan warna daun.

Kata kunci: kecambah benih pala, Myristicaceae, perlakuan kulit benih 


\section{PENDAHULUAN}

Pala (Myristica fragrans) merupakan komoditas rempah asli Indonesia yang sebagian besar berasal dari daerah Maluku. Pala memiliki nilai ekonomi yang tinggi sebab komoditas ini menjadi andalan sumber devisa bagi ekspor non migas dalam bentuk biji pala, fuli, dan pala glondong. Indonesia mampu memenuhi kebutuhan $60 \%$ hingga $75 \%$ pangsa pasar dunia yang diikuti negara lain, seperti Grenada, India, Sri Langka, dan Papua New Guinea (Bustaman 2008; Alegantina dan Mutiatikum 2009). Volume ekspor pala yang berupa biji kering dan fuli kering pada triwulan pertama tahun 2014 mencapai 3.04 ribu ton dengan nilai jual hingga US\$ 24.57 juta (Kementan 2014). Potensi pengembangan pala selanjutnya adalah meningkatkan produksi dengan perluasan wilayah penanaman pala yang mencapai 3600 ha, penggunaan bahan tanam yang unggul, dan pendampingan petani pala (Ditjenbun, 2012).

Kebutuhan bahan tanam yang cepat untuk memenuhi permintaan yang cukup besar tersebut akan terkendala pada lamanya perkecambahan benih pala. Penggunaan biji sebagai perbanyakan tanaman pala perlu mendapat perlakuan khusus sebelum benih ditanam karena benih pala memiliki struktur kulit yang sangat keras. Proses perkecambahan benih pala membutuhkan waktu paling cepat tiga bulan bila benih tidak mendapatkan perlakuan khusus. Masa ini disebut dengan masa dormansi yang disebabkan oleh struktur fisik benih sehingga imbibisi air terhambat (Arrijani 2005).

Beberapa upaya untuk mengatasi hambatan fisik benih dalam upaya meningkatkan perkecambahan telah dilakukan oleh beberapa peneliti. Perlakuan benih pala dengan penghilangan kulit benih dapat meningkatkan daya berkecambah sebesar $62.00 \%$ dibandingkan perlakuan kimia menggunakan $\mathrm{H}_{2} \mathrm{SO}_{4} 18 \mathrm{~N}(0.00 \%)$ dan $\mathrm{KNO}_{3} \quad 0.2 \%$ (26.00\%) atau perendaman air panas $(0.00 \%)$ pada 100 hari setelah tanam (Ramadhan 2007). Penelitian lain pada benih palahar (Dipterocarpus retusus BL) yang dilakukan oleh Sartika (2003) dengan perlakuan pengupasan kulit benih berpengaruh sangat nyata dalam meningkatkan daya berkecambah benih sebesar $14.47 \%$ dibandingkan pada benih yang tidak dikupas kulitnya sebesar $5.26 \%$ pada pengamatan selama 81 hari. Perlakuan pematahan dormansi selain penghilangan kulit benih yang keras juga dapat dilakukan dengan cara skarifikasi, yakni pengikisan kulit benih. Benih aren pada penelitian Saleh et al. (2008) yang diberi perlakuan skarifikasi + perendaman $\mathrm{KNO}_{3} 0.5 \% 36 \mathrm{jam}+$ suhu $40^{\circ} \mathrm{C}$ yang ditanam pada media campuran tanah dari hutan aren dan bahan organik (1:1) menghasilkan daya berkecambah nyata lebih baik sebesar $86.67 \%$ pada 90 hari setelah tanam.

Faktor lain yang mempengaruhi perkecambahan benih adalah media perkecambahan. Media perkecambahan juga memiliki peranan penting dalam membantu mempercepat perkecambahan dan setiap benih akan memiliki respon yang berbeda-beda untuk perkecambahan terhadap media tertentu. Penelitian terhadap pengaruh jenis media perkecambahan secara spesifik bagi benih pala belum banyak dilakukan di Indonesia. Khandekar et al. (2006) melakukan penelitian mengenai media perkecambahan benih pala di Maharashtra, India menyatakan media dedak padi dapat mempercepat benih pala berkecambah pada 27.2 hari setelah tanam, kemudian diikuti oleh media campuran pasir dan dedak padi (28.1 hari) serta media pasir (28.5 hari). Penelitian lain oleh Abirami et al. (2010) mengenai media perkecambahan benih pala yang menggunakan media campuran vermikompos dan serabut kelapa mampu mempercepat kemunculan kecambah pada 42.10 hari setelah tanam yang dilakukan di Kerala, India. Penelitian ini bertujuan mempelajari perlakuan skarifikasi fisik kulit benih pala dan penggunaan media perkecambahan dalam upaya mempercepat perkecambahan dan meningkatkan viabilitas benih pala.

\section{BAHAN DAN METODE}

Penelitian ini dilaksanakan pada bulan Desember 2013 hingga bulan Mei 2014 di green house Kebun Percobaan Leuwikopo dan Laboratorium Benih Departemen Agronomi dan Hortikultura, Fakultas Pertanian, Institut Pertanian Bogor. Benih yang digunakan yakni benih pala yang telah mencapai masak fisiologi. Media yang digunakan adalah kompos, arang sekam, dan pasir serta fungisida yang berbahan aktif mankozeb $80 \%$. Alat-alat yang digunakan antara lain bak plastik ukuran $38 \mathrm{~cm} \times$ $32 \mathrm{~cm} \times 10 \mathrm{~cm}$, boks plastik besar, mesin gerinda tipe bench grinder MD-150, oven, desikator, cawan aluminium, hydrogell, polibag, paranet, gembor, timbangan digital, jangka sorong, bor listrik, pisau, saringan alumunium, alat tulis, dan label.

Benih pala yang digunakan berasal dari tiga lokasi yang berbeda di Provinsi Maluku. Lokasi pertama yakni Desa Liliboi, Kecamatan Leihitu Barat, Kabupaten Maluku Tengah. Lokasi sumber benih kedua yakni Dusun Toisapu, Desa 
Hutumuri, Kecamatan Leitimur Selatan, Kota Ambon dan lokasi ketiga yakni Desa Wakal, Kecamatan Leihitu, Kabupaten Maluku Tengah. Benih dipanen pada minggu kedua bulan Desember 2013. Karakter masing-masing benih yang berasal dari tiga lokasi tersebut dapat dilihat pada Tabel 1.

Tabel 1. Karakter benih pala yang berasal dari tiga lokasi yang berbeda di Provinsi Maluku

\begin{tabular}{lccc}
\hline \multicolumn{1}{c}{ Parameter yang } & \multicolumn{3}{c}{ Sumber benih } \\
\cline { 2 - 4 } \multicolumn{1}{c}{ diamati } & Liliboi & Toisapu & Wakal \\
\hline Bentuk benih & Oval & Oval & Bulat \\
Bobot benih $(\mathrm{g})$ & 8.09 & 7.91 & 8.88 \\
Diameter benih $(\mathrm{cm})$ & 2.22 & 2.22 & 2.37 \\
Panjang benih $(\mathrm{cm})$ & 2.76 & 2.63 & 2.64 \\
Kadar air benih $(\%)$ & 33.73 & 41.37 & 42.78 \\
\hline
\end{tabular}

Percobaan ini menggunakan rancangan percobaan faktorial dengan rancangan lingkungan rancangan kelompok lengkap teracak (RKLT). Percobaan terdiri atas dua faktor dengan tiga kali ulangan setiap faktornya. Faktor pertama adalah perlakuan skarifikasi fisik kulit benih dengan tiga taraf perlakuan, yaitu tanpa perlakuan skarifikasi (S0), skarifikasi satu lubang bagian pangkal benih (S1), dan skarifikasi dua lubang bagian ujung dan pangkal benih (S2). Faktor kedua adalah jenis media perkecambahan benih yang terdiri dari tiga taraf, yakni pasir (M1), arang sekam (M2), dan campuran antara pasir dengan kompos 1:1 (v/v) (M3). Penelitian ini terdiri atas 9 kombinasi percobaan dengan 27 satuan percobaan. Setiap satuan percobaan terdiri dari 25 benih sehingga jumlah benih yang dibutuhkan sebanyak 675 benih pala. Uji F dilakukan untuk melihat ada tidaknya perbedaan antar perlakuan dan akan dilanjutkan dengan uji selang berganda Duncan (DMRT) apabila terdapat perbedaan nyata pada taraf 5\%. Pengolahan data untuk pengujian tersebut menggunakan perangkat lunak statistical analysis system (SAS).

Benih pala diekstraksi dengan membelah buah menggunakan pisau dan fuli (selaput benih) dipisahkan dari kulit benih. Benih diambil 6 butir dan diiris menggunakan mesin pengiris dari masing-masing lokasi untuk diukur kadar airnya dengan metode oven suhu $105{ }^{\circ} \mathrm{C}$ selama 17 jam. Benih-benih lainnya dikumpulkan dalam boks plastik besar yang sudah berisi hydrogell untuk menjaga kelembapan benih pala. Beberapa benih diambil untuk ditimbang bobot benih menggunakan timbangan digital. Benih tersebut juga diukur panjang dan diameter benih menggunakan jangka sorong. Benih kemudian diberi fungisida dengan konsentrasi $2 \mathrm{~g}$ per liter air yang telah dilarutkan dalam bak plastik dan direndam selama 10 menit. Benih kemudian dicuci dengan air bersih dan ditiriskan lalu dikeringanginkan agar mudah dilakukan skarifikasi fisik.

Perlakuan skarifikasi benih dilakukan menggunakan mesin gerinda listrik dengan cara menempelkan kulit benih ke piringan gerinda yang berputar dengan kecepatan 2950 rpm. Kulit benih dicek setiap rentang waktu beberapa detik agar proses skarifikasi tidak sampai merusak bagian permukaan embrio benih dan mencegah kegosongan. Benih yang telah diskarifikasi diberi fungisida kembali dan ditanam sebanyak 25 butir per bak serta ditempelkan kertas label identitas perlakuan. Benih ditanam seperti metode di atas pasir (top of sand) yaitu benih hanya ditekan di atas permukaan media sedalam $2 \mathrm{~cm}$. Paranet diberikan selama proses pengujian dalam green house agar kondisi tetap teduh. Pemeliharaan rutin dilakukan setiap satu hari sekali terhadap kondisi media perkecambahan agar tetap lembap. Media perkecambahan disiram air dengan menggunakan gembor setiap hari.

Pengamatan viabilitas benih pala dilakukan dalam dua waktu yang berbeda, yakni saat kecambah di bak perkecambahan dan saat akan dipindahtanamkan. Parameter yang diamati pada kecambah saat masih berada di bak perkecambahan yakni potensi tumbuh ma ksimum (PTM) yang diamati hingga akhir pengamatan, daya berkecambah (DB) yang diamati pada hari ke-52 dan hari ke-88 setelah tanam, kecepatan tumbuh $\left(\mathrm{K}_{\mathrm{CT}}\right)$ yang diamati setelah hari ke-10 setelah tanam dengan interval pengamatan selanjutnya per lima hari, hari kemunculan akar, dan hari kemunculan tunas. Parameter yang diamati pada saat akan dipindahtanamkan meliputi diameter akar yang diukur $1 \mathrm{~cm}$ dari bawah kotiledon benih, panjang akar yang diukur dari batas antara akar dan batang, jumlah akar lateral, diameter tunas yang diukur $1 \mathrm{~cm}$ di atas kotiledon benih, tinggi tunas yang diukur dari batas antara akar dan tunas, dan jumlah daun.

Kecambah-kecambah yang tumbuh dari salah satu perlakuan skarifikasi kemudian diamati kembali pada masa pembibitan selama 7 minggu. Kecambah-kecambah tersebut dipindahtanamkan ke dalam polibag berukuran 20 $\mathrm{cm} \times 40 \mathrm{~cm}$ dengan media campuran antara tanah dan kompos 2:1 (v/v). Polibag tersebut masingmasing berisi satu kecambah. Pembibitan pala ini dilakukan di dalam green house dan dinaungi oleh paranet. Pemeliharaan yang dilakukan yaitu penyiraman dan pengendalian gulma secara manual. Parameter yang diamati setiap minggu 
antara lain diameter batang yang diukur dipangkal batang, tinggi bibit yang diukur dari permukaan media hingga titik tumbuh bibit pala, jumlah daun, luas daun dengan metode gravimetri, lebar tajuk yang diukur pada lebar rentangan daun bibit pala, dan warna daun yang diukur menggunakan bagan warna daun. Data yang diperoleh dilakukan Uji-t dengan selang kepercayaan 95\% dan dibandingkan antar perlakuan setiap minggunya.

\section{HASIL DAN PEMBAHASAN}

\section{Viabilitas Benih Pala}

Perlakuan skarifikasi fisik dengan pelukaan mekanik kulit benih dapat membantu imbibisi air akibat impermeabilitas kulit benih. Tabel 1 menunjukkan perlakuan skarifikasi dua lubang mempercepat kemunculan akar karena perlakuan tersebut memberikan celah untuk imbibisi air. Kemunculan akar dapat diinisiasi pada hari ke-33 setelah benih disemai. Tunas muncul pada hari ke-59 setelah penyemaian benih atau 26 hari setelah kemunculan akar (Tabel 2). Penelitian Widyawati et al. (2009) pada benih aren yang telah diampelas di bagian operkulumnya berpengaruh nyata meningkatkan pemunculan embrio pada 7 hari setelah semai (HSS) sebesar $36.67 \%$ dan pada 10 HSS sebesar
78.33\% dibandingkan dengan perlakuan benih tanpa diampelas yang menunjukkan persentase nol pada 7 HSS dan 10 HSS. Perlakuan skarifikasi pada benih aren dalam penelitian Maryani dan Irfandri (2008) yang dilakukan di tempat keluarnya embrio nyata mempercepat umur berkecambah benih tersebut yakni pada 40.57 HSS dibandingkan benih aren tanpa perlakuan skarifikasi pada 56.58 HSS. Hal ini disebabkan perlakuan skarifikasi dapat menipiskan kulit benih aren sehingga kebutuhan benih terhadap air dan oksigen cepat tersedia dalam jumlah yang cukup untuk perkecambahan.

Perlakuan skarifikasi dua lubang juga menghasilkan tinggi tunas kecambah pala yang nyata lebih tinggi dibandingkan perlakuan lainnya (Tabel 2). Hal ini diduga setelah pertumbuhan akar kecambah pala yang lebih cepat dapat membantu penyerapan air lebih baik yang kemudian memicu pemanjangan dan perkembangan sel. Penelitian pada perkecambahan benih barli juga menunjukkan awal mula pertumbuhan akar lembaga (radikula) yang lebih cepat daripada pucuk lembaga (plumula) memberikan keuntungan bagi pertumbuhan kecambah barli tersebut. Hal ini ditunjukkan oleh akumulasi berat kering pada pucuk lebih besar dibandingkan pada akar dalam waktu 21 hari setelah semai (Gardner et al. 1991).

Tabel 2. Pengaruh skarifikasi fisik terhadap perkecambahan benih pala

\begin{tabular}{cccc}
\hline Perlakuan & Hari muncul akar (hari) & Hari muncul tunas (hari) & Tinggi tunas (cm) \\
\hline Tanpa skarifikasi & $44.44 \mathrm{a}$ & $74.23 \mathrm{a}$ & $2.75 \mathrm{~b}$ \\
Skarifikasi 1 lubang & $47.85 \mathrm{a}$ & $74.17 \mathrm{a}$ & $2.69 \mathrm{~b}$ \\
Skarifikasi 2 lubang & $33.71 \mathrm{~b}$ & $59.74 \mathrm{a}$ & $7.53 \mathrm{a}$ \\
\hline
\end{tabular}

Angka-angka pada kolom yang sama yang diikuti oleh huruf yang sama tidak berbeda nyata pada taraf uji 5\% (uji selang berganda Duncan).

Media pasir menghasilkan potensi tumbuh maksimum (PTM) yang sama dengan media arang sekam pada perkecambahan benih pala (Tabel 3). Hal ini juga ditunjukkan pada penelitian benih leci yang ditanam pada media pasir memiliki nilai PTM yang sama dengan media arang sekam yakni $73.81 \%$ dan $83.33 \%$ pada tujuh hari setelah tanam (De Andrade et al., 2004). Hasil penilitian lain oleh Rofik dan Murniati (2008) dengan tolok ukur PTM dan daya berkecambah (DB) pada benih aren yang telah dideoperkulasi (pengamplasan kulit benih tepat pada titik tumbuh) dan ditanam pada media pasir memiliki nilai $95.00 \%$ dan $88.33 \%$ menunjukkan pengaruh yang sama pada media arang sekam dengan nilai $86.67 \%$ dan $85.00 \%$.

Benih pala yang ditanam pada media arang sekam menghasilkan pertumbuhan yang lebih lambat dibandingkan benih pala yang ditanam pada media pasir. Hal ini tampak pada rendahnya nilai DB yang menunjukkan jumlah kecambah normal pala yang ditanam pada media arang sekam (Tabel 3). Banyaknya kecambahkecambah yang abnormal pada media arang sekam diduga karena kondisi air yang kurang tersedia. Air yang diberikan pada media arang sekam saat pemeliharaan rutin tidak dapat dipertahankan dengan baik dibandingkan pada media pasir yang cenderung tampak lebih lembab setelah penyiraman. Penelitian pada perkecambahan benih mengkudu dengan media pasir juga menunjukkan pertumbuhan yang lebih baik dengan tolok ukur PTM dan DB sebesar $80.20 \%$ dan $74.40 \%$ dibandingkan pada media arang sekam dengan nilai $25.00 \%$ dan $24.50 \%$ (Murniati dan Suminar, 2006).

Kecambah pala yang ditanam pada media pasir dan media campuran pasir dan kompos 
memiliki pertumbuhan tinggi tunas yang nyata lebih tinggi dibandingkan pada media arang sekam (Tabel 3). Perkecambahan benih pala pada media pasir menunjukkan tinggi tunas yang tinggi dapat diduga karena kecambah tersebut telah berkembang menjadi kecambah normal dan memiliki jumlah akar lateral yang cukup baik. Media campuran antara pasir dan kompos mampu meningkatkan kondisi fisik dan komposisi nutrisi media sehingga diduga dapat mempengaruhi tinggi tunas kecambah pala. Penelitian pada bibit pala yang ditanam pada kombinasi media organik, berupa vermikompos dan serbuk kelapa nyata lebih baik dengan tinggi bibit mencapai $26.98 \mathrm{~cm}$ (Abirami et al., 2010). Hasil penelitian serupa ditunjukkan pada perkecambahan benih mengkudu yang ditanam pada media campuran tanah dan kompos memiliki panjang epikotil sebesar $4.90 \mathrm{~cm}$ nyata lebih baik dibandingkan panjang epikotil pada media pasir $(0.80 \mathrm{~cm})$ dan media arang sekam $(0.20 \mathrm{~cm})$ (Murniati dan Suminar, 2006).

Tabel 3. Pengaruh media perkecambahan terhadap perkecambahan benih pala

\begin{tabular}{llcc}
\hline \multicolumn{1}{c}{ Perlakuan } & PTM $(\%)$ & DB $(\%)$ & $\begin{array}{c}\text { Tinggi tunas } \\
(\mathrm{cm})\end{array}$ \\
\hline Pasir & $11.11 \mathrm{ab}$ & 2.67 & $7.13 \mathrm{a}$ \\
Arang sekam & $13.33 \mathrm{a}$ & 0.00 & $1.58 \mathrm{~b}$ \\
Pasir + kompos & $2.22 \mathrm{~b}$ & 0.89 & $6.43 \mathrm{a}$ \\
\hline
\end{tabular}

Angka-angka pada kolom yang sama yang diikuti oleh huruf yang sama tidak berbeda nyata pada taraf uji 5\% (uji selang berganda Duncan).
Benih pala yang diskarifikasi 2 lubang dan ditanam pada media pasir menunjukkan jumlah akar lateral yang paling banyak dibandingkan pada perlakuan lainnya (Tabel 4). Hal ini diduga kemunculan akar yang lebih awal dapat memicu pertumbuhan akar lateral dan dipermudah pertumbuhannya pada media pasir. Kemunculan akar yang lebih awal pada perlakuan tersebut menyebabkan bagian-bagian lain kecambah pala berkembang lebih dahulu, termasuk akar lateral. Gardner et al. (1991) menyatakan fungsi penting akar yaitu berperan dalam penyerapan air dan mineral yang mempengaruhi pertumbuhan dan perkembangan tanaman. Akar lateral berasal dari meristem yang terbentuk di dalam lingkaran tepi beberapa centimeter dari ujung akar. Pembentukan akar lateral ini dikendalikan secara genetik akan tetapi juga sangat dipengaruhi oleh lingkungan (Gardner et al., 1991). Media perkecambahan merupakan salah satu faktor lingkungan yang dapat mempengaruhi pertumbuhan akar lateral pada kecambah pala. Penelitian Sumiasri dan Setyowati (2006) mengenai perkecambahan benih eboni yang ditanam pada media pasir menghasilkan perakaran yang baik karena media pasir memiliki porositas yang tinggi sehingga mudah ditembus oleh akar kecambah eboni. Lestari et al. (2011) juga menyatakan media pasir sangat baik bagi pertumbuhan bibit salak karena memberikan aerasi untuk pertumbuhan akar dan memberikan ketersediaan nutrisi yang cukup.

Tabel 4. Interaksi perlakuan skarifikasi fisik dan media perkecambahan pada jumlah akar lateral kecambah benih pala

\begin{tabular}{llll}
\hline \multirow{2}{*}{\multicolumn{1}{c}{ Perlakuan skarifikasi }} & \multicolumn{3}{c}{ Perlakuan media } \\
\cline { 2 - 4 } & Pasir & Arang sekam & Pasir + kompos \\
\hline Tanpa skarifikasi & $1.86 \mathrm{c}$ & $0.94 \mathrm{~d}$ & $0.00 \mathrm{~d}$ \\
Skarifikasi 1 lubang & $0.32 \mathrm{~d}$ & $0.40 \mathrm{~d}$ & $0.00 \mathrm{~d}$ \\
Skarifikasi 2 lubang & $6.00 \mathrm{a}$ & $1.07 \mathrm{~cd}$ & $3.00 \mathrm{~b}$ \\
\hline
\end{tabular}

Angka-angka pada kolom yang sama yang diikuti oleh huruf yang sama tidak berbeda nyata pada taraf uji 5\% (uji selang berganda Duncan).

\section{Pertumbuhan Bibit Pala di Polibag}

Perkembangan diameter batang bibit pala dari masing-masing kecambah hasil perlakuan benih di awal tampak pada Gambar 1. Bibit-bibit tersebut memiliki diameter yang hampir sama pada 1 MSP. Kecambah yang berasal dari media pasir memiliki perkembangan diameter batang yang meningkat tiap minggunya. Pengukuran akhir menunjukkan diameter batang pada perlakuan ini mencapai $4.75 \mathrm{~mm}$. Pertumbuhan bibit pala yang berasal dari kecambah pada media arang sekam mengalami peningkatan yang cukup baik. Diameter batang bibit pala tersebut pada 7 MSP terukur $4.44 \mathrm{~mm}$ dan setiap minggunya mengalami peningkatan.

Pertumbuhan tinggi bibit pala setelah masa perkecambahan dapat terlihat pada. Tinggi bibit pada kecambah yang berasal dari media pasir menunjukkan pertumbuhan yang cukup signifikan. Pertambahan tinggi bibit ini terus meningkat setiap minggunya. Tinggi bibit pada perlakuan ini mencapai $14.19 \mathrm{~cm}$ pada akhir pengamatan. Kecambah yang berasal dari media arang sekam juga menunjukkan peningkatan pada parameter tinggi bibit yang 
mencapai $10.10 \mathrm{~cm}$ pada akhir pengamatan. Bibit pala yang berasal dari kecambah pada media arang sekam juga menunjukkan peningkatan yang cukup baik setiap minggunya.
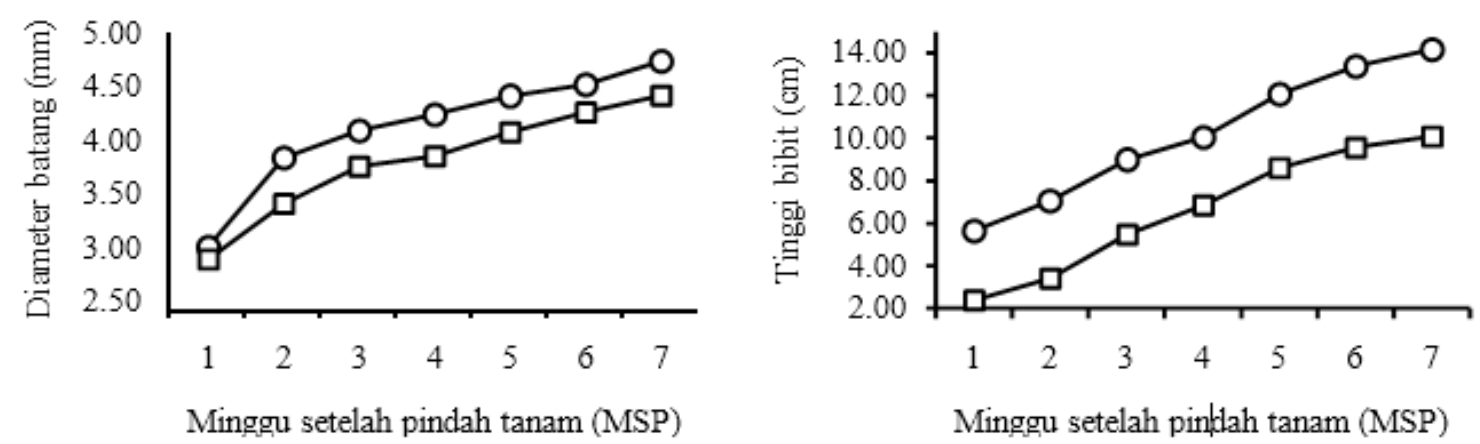

Gambar 1. Pengukuran diameter batang dan tinggi bibit pala yang berasal dari perkecambahan pada media pasir (०) dan media arang sekam ( $\square$ )

Bibit pala hasil perkecambahan dengan media pasir mengalami pertumbuhan yang stagnan pada 3 MSP hingga 5 MSP sebesar 1.67 helai. Perhitungan akhir jumlah daun pada perlakuan ini mencapai 3.33 helai daun. Perlakuan awal benih pala yang ditanam pada media arang sekam memulai pertumbuhan jumlah daunnya pada 2 MSP. Peningkatan jumlah daun pada perlakuan ini meningkat setiap minggunya akan tetapi menunjukkan pertumbuhan yang stagnan pada periode 6 MSP hingga 7 MSP dan mencapai 2.33 helai daun pada 7 MSP (Gambar 2).

Pengamatan luas daun pada bibit pala dapat terlihat pada Gambar 2. Bibit pala yang berasal dari kecambah yang ditanam pada media pasir mengalami peningkatan yang sangat signifikan pada rentang pengamatan 5 MSP hingga 7 MSP. Perkembangan luas daun mencapai $102.85 \mathrm{~cm}^{2}$ pada akhir pengamatan. Bibit pala yang berasal dari kecambah yang ditanam pada media arang sekam memulai perkembangannya pada 2 MSP. Perkembangan luas daunnya cenderung lambat pada 3 MSP hingga 4 MSP akan tetapi lonjakan peningkatan luas daun terjadi saat 5 MSP hingga 7 MSP. Luas daun tersebut meningkat dari $12.27 \mathrm{~cm}^{2}$ menjadi $72.73 \quad \mathrm{~cm}^{2} \quad$ (Gambar 2 ).

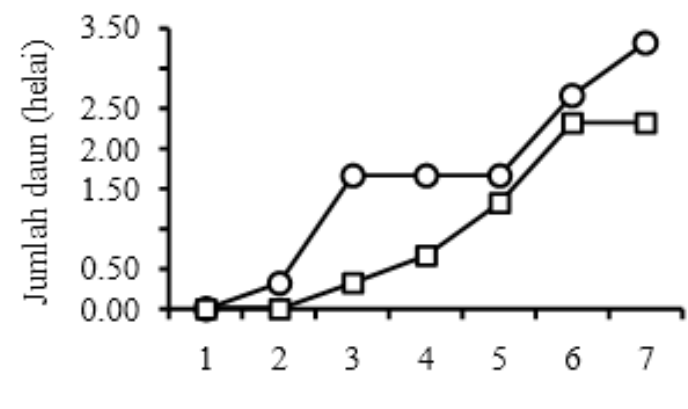

Minggu setelah pindah tanam (MSP)

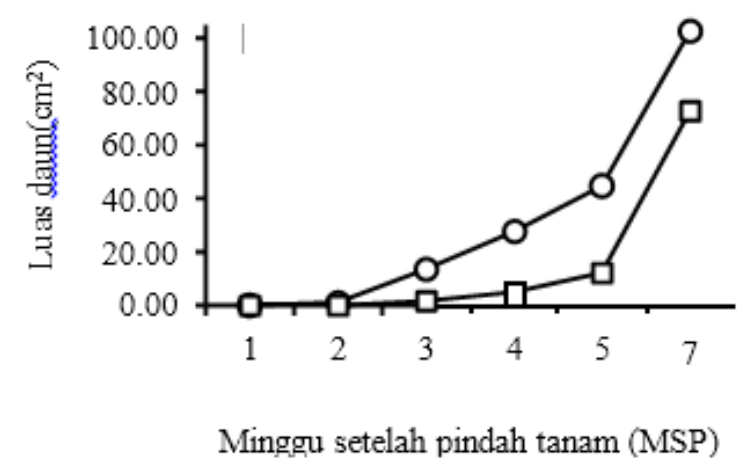

Minggu setelah pindah tanam (MSP)

Gambar 2. Pengukuran jumlah daun dan luas daun bibit pala yang berasal dari perkecambahan pada media pasir (०) dan media arang sekam ( $\square$ )

Perkembangan lebar tajuk dapat terlihat pada Gambar 3 yang menggambarkan penambahan luas daun bibit pala. Daun yang semakin luas dapat diamati penutupan tajuknya juga yang semakin lebar. Bibit pala yang berasal dari perkecambahan pada media pasir memulai perkembangannya pada 2 MSP sebesar $1.66 \mathrm{~cm}$. Perkembangannya semakin meningkat hingga 7 MSP sebesar $23.47 \mathrm{~cm}$. Lebar tajuk bibit pala yang berasal dari perkecambahan pada media arang sekam dimulai saat 3 MSP yang terus meningkat perkembangannya hingga mencapai $16.79 \mathrm{~cm}$ pada $7 \mathrm{MSP}$.

Warna daun pada bibit pala mengalami perubahan pada 1 MSP hingga 7 MSP (Gambar 3). Perubahan tersebut dinyatakan dengan nilai bagan warna daun yang meningkat setiap minggunya. Warna daun pada bibit pala yang 
berasal dari perkecambahan pada media pasir dapat diukur setelah daun tumbuh pada 2 MSP. Warna daun bibit tersebut mengalami peningkatan dan mencapai skala 3.43 pada 7 MSP yang menandakan daun semakin hijau. Bibit pala hasil perkecambahan pada media arang sekam mulai tampak perubahan warna daunnya pada 3 MSP hingga 7 MSP. Pengukuran akhir warna daun pada bibit tersebut mencapai skala 2.07 saat 7 MSP dan daun terlihat hijau dibandingkan minggu-minggu sebelumnya.

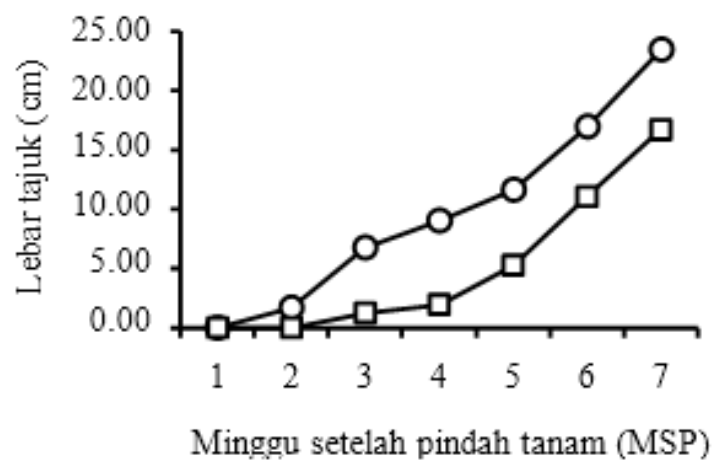

Kecambah dengan skarifikasi 1 lubang yang berasal dari media pasir menunjukkan pertumbuhan bibit pala sampai 7 MSP lebih baik berdasarkan parameter diameter batang, tinggi bibit, jumlah daun, luas daun, lebar tajuk, dan warna daun. Hal ini menunjukkan media pasir merupakan media yang paling baik digunakan pada saat perkecambahan benih pala. Kecambah yang tumbuh normal pada saat perkecambahan mampu tumbuh baik pada fase berikutnya karena bagian-bagian esensial dari suatu tanaman sudah terbentuk dari awal dengan baik.

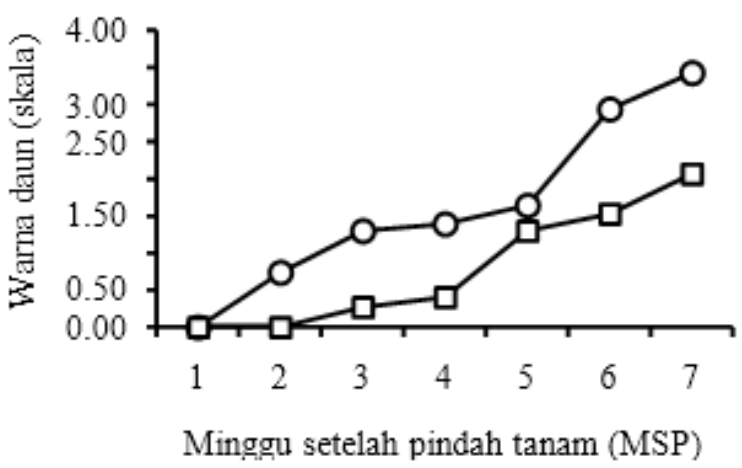

Gambar 3. Pengukuran lebar tajuk dan warna daun bibit pala yang berasal dari perkecambahan pada media pasir (०) dan media arang sekam ( $\square)$

\section{KESIMPULAN}

Perlakuan skarifikasi fisik dua lubang dapat meningkatkan perkecambahan benih pala berdasarkan kemunculan akar (33.17 HST) dan kemunculan tunas (59.74 HST). Media pasir merupakan media yang nyata lebih baik berdasarkan tolok ukur daya berkecambah $(2.67 \%)$ dan tinggi tunas $(7.13 \mathrm{~cm})$. Skarifikasi benih pala dua lubang yang ditanam di media pasir menunjukkan jumlah akar lateral nyata lebih banyak sejumlah enam buah. Pertumbuhan bibit pala selama tujuh minggu setelah pindah tanam dengan kecambah yang berasal dari media pasir menunjukkan hasil yang lebih baik dibandingkan kecambah dari media arang sekam pada parameter diameter batang, tinggi bibit, jumlah daun, lebar tajuk, dan warna daun.

\section{DAFTAR PUSTAKA}

Abirami, K., Rema, J., Mathew, P.A., Srinivasan, V., Hamza, S. 2010. Effect of different propagation media or seed germination, seedling growth and vigor of nutmeg (Myristica fragrans). J. Med Plant Res. 4(19):2054-2058.
Alegantina, S., Mutiatikum, D. 2009. Pengembangan dan potensi pala (Myristica fragrans). J Kefarmasi Indo. 1(2):64-70.

Arrijani. 2005. Biologi dan konservasi marga Myristica di Indonesia. Biodiversitas. 6(2):147-151.

Bustaman, S. 2008. Prospek pengembangan minyak pala banda sebagai komoditas ekspor Maluku. $J$ Litbang Pert. 27(3):93-98.

De Andrade, R.A., Martins, A.B.G., De Morais Oliveira, I.V. 2004. Influence of the substrate in germination of lychee seeds. Rev Bras Frutic. 26(2):375-376.

[Ditjenbun] Direktorat Jendral Perkebunan. 2012. Pedoman Teknis Perluasan Tanaman Pala Tahun 2012. Direktorat Jendral Perkebunan, Kementerian Pertanian, Jakarta.

Gardner, F.P., Pearce, R.B., Mitchell, R.L. 1991. Fisiologi Tanaman Budidaya. Susilo H, penerjemah. UI Pr, Jakarta. Terjemahan dari: Physiology of Crop Plants. 
Khandekar, R.G., Dashora, L.K., Joshi, G.D., Haldankar, P.M., Gadre, U.A., Jain, M.C., Haldavnekar, P.C., Pande, V.S. 2006. Effect of rooting media on germination and seedling growth of nutmeg (Myristica fragrans Houtt). J Spic Aromatic Crops. 15(2):100-104.

Lestari, R., George, E., Huyskens-Keil, S. 2011. Growth and physiological responses of salak cultivars (Salacca zalacca (Gaertn) Voss) to different growing media. J Agric Sci. 3(4):261-271.

Maryani, A.T., Irfandri. 2008. Pengaruh skarifikasi dan pemberian giberelin terhadap perkecambahan benih tanaman aren (Arenga pinnata (Wurmb.) Merr.). SAGU. 7(1):1-6.

Murniati, E., Suminar, M. 2006. Pengaruh jenis media perkecambahan dan perlakuan pra perkecambahan terhadap viabilitas benih mengkudu (Morinda citrifolia $\mathrm{L}$.) dan hubungannya dengan sifat dormansi benih. Bul Agron. 34(2):119-123.

Ramadhan, R. 2007. Pematahan dormansi pada tingkat kemasakan dalam upaya mempercepat perkecambahan benih pala banda (Myristica fragrans Houtt). [Skripsi]. Institut Pertanian Bogor, Bogor.
Rofik, A., Murniati, E. 2008. Pengaruh perlakuan deoperkulasi benih dan media perkecambahan untuk meningkatkan viabilitas benih aren (Arenga pinnata (Wurmb.) Merr.). Bul Agron. 36(1):33-40.

Saleh, M, S., Adelina, E., Murniati, E., Budiarti, T. 2008. Pengaruh skarifikasi dan media tumbu $\mathrm{h}$ terhadap viabilitas benih dan vigor kecambah aren. J Agroland. 15(3):182190.

Sartika, C. 2003. Pengaruh media semai dan perlakuan kulit biji terhadap kinerja perkecambahan palahar (Dipterocarpus retusus BL). [Skripsi]. Institut Pertanian Bogor, Bogor.

Sumiasri, N., Setyowati, N. 2006. Pengaruh beberapa media pada pertumbuhan bibit eboni (Diospyros celebica Bakh) melalui perbanyakan biji. Biodiversitas. 7(3): 260-263.

Widyawati, N., Tohari., Yudono, P., Soemardi, I. 2009. Permeabilitas dan perkecambahan benih aren (Arenga pinnata (Wurmb.) Merr.). J Agron Indonesia. 37(2):152158. 